\title{
Post-traumatic giant occipital pseudomeningocele
}

\author{
Priyanka P. Karnik, MD • Nandini M. Dave, MD • Rachana Chhabria, MD • \\ Madhu Garasia, MD • Harick Shah, MD
}

Received: 7 November 2015/Revised: 10 November 2015/Accepted: 18 November 2015/Published online: 24 November 2015

(C) Canadian Anesthesiologists' Society 2015

Pseudomeningoceles are collections of cerebrospinal fluid (CSF) in the extradural space due to a defect in the duralarachnoid layers of the meninges. Post-traumatic pseudomeningoceles are rare and usually seen in the cervical region, but they can also occur in the lumbosacral region. Although most patients are asymptomatic, some present with a wide variety of symptoms, including headache, back or neck pain, radicular pain, or motor deficits due to entrapment of nerves. All the patients have a fluctuant swelling that increases in size on Valsalva maneuver (e.g., coughing or sneezing). Giant pseudomeningoceles are considered those that are greater than $8 \mathrm{~cm}$ in length. ${ }^{1}$ Herein, we report the case of a giant occipital pseudomeningocele in an 11-mth-old child presenting 20 days following occipital trauma.

Tracheal intubation was performed with the child in the lateral position to avoid pressure on the swelling. Central venous and arterial catheters were then inserted using ultrasonography guidance due to an unclear preoperative diagnosis presenting the possibility of communication with the venous sinus. On exploration, we found the swelling to be a pseudomeningocele and the dural defect was closed uneventfully. The child's trachea was extubated at the end of procedure (Figure).

It is crucial to avoid pressure on the pseudomeningocele during positioning and intubation to prevent injury to neural elements as well as an increase in CSF pressure that may result in cerebral ischemia. ${ }^{2}$ Laryngoscopy and intubation can be performed in the lateral position (as in this case) or by supporting the patient's head beyond the edge of the table. Accurate assessment of blood loss may be difficult due to the mixing of CSF and blood. Placement of a subarachnoid catheter preoperatively has also been advocated in a few cases of giant pseudomeningoceles to prevent raised intracranial pressure and its associated symptoms such as bradycardia, hypertension, and irregular breathing (i.e., Cushing's triad). ${ }^{1}$

P. P. Karnik, MD ( $₫) \cdot$ N. M. Dave, MD - R. Chhabria, MD ·

M. Garasia, MD · H. Shah, MD

Department of Paediatric Anesthesiology, Seth G.S. Medical

College, K.E.M. Hospital, Mumbai, India

e-mail:piyu_85007@yahoo.com 


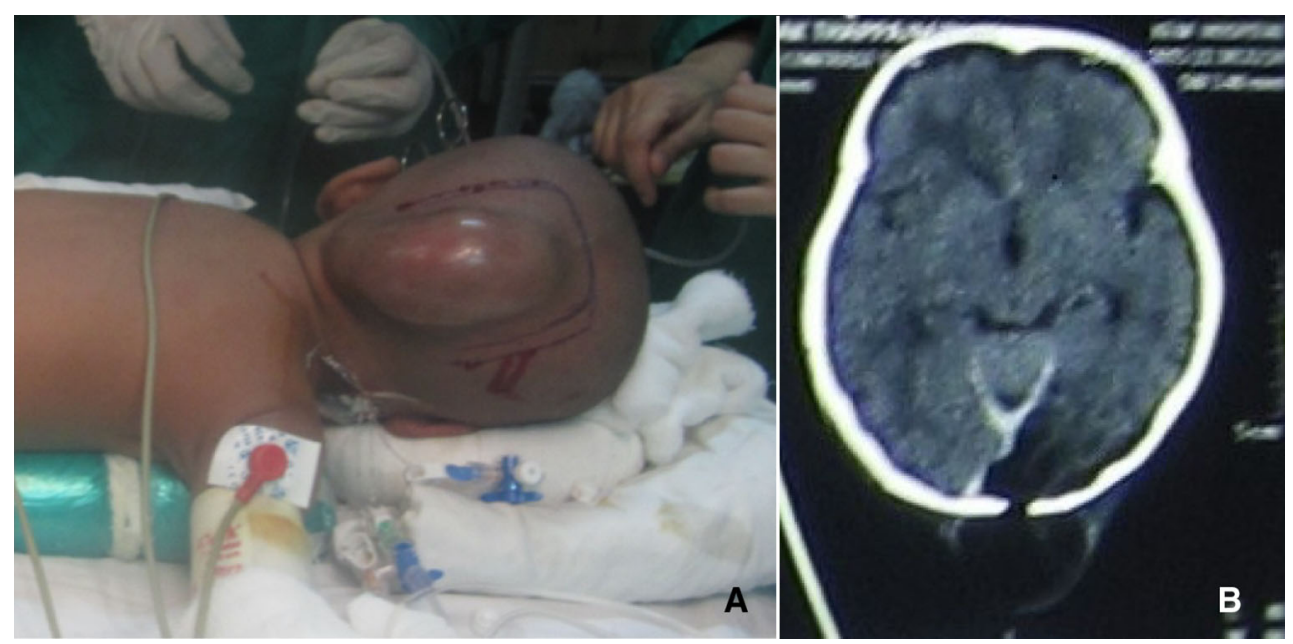

Figure The left image (A) depicts the intraoperative patient positioning and preparation prior to beginning surgery on this patient with a giant pseudomeningocele. The blood seen in the

Conflicts of interest None declared.

\section{References}

1. Weng YJ, Cheng CC, Li YY, Huang TJ, Hsu RW. Management of giant pseudomeningoceles after spinal surgery. BMC Musculoskelet Disord 2010; 11: 53. photograph is due to local anesthetic infiltration. The right image (B) is the corresponding patient computed tomography scan showing the pseudomeningocele and underlying traumatic skull defect

2. Drummond JC, Ciacci JD, Lee RR. Direct pressure on a pseudomeningocele resulting in intraoperative cerebral ischemia. Can J Anesth 2014; 61: 656-9. 